\title{
Enhanced Peripheral Blood T lymphocyte Apoptosis in Pulmonary Tuberculosis: Correlation with Disease Severity as Reflected by Mycobacterial Load
}

\author{
Amal Abd El Nabi Ayoub, Effat Moustafa Hassan, Azza Hassan El Salakawy and Amany M. Tawfeik* \\ Department of Microbiology, Faculty of Medicine, Al Azhar University \\ *Corresponding author: Amany M. Tawfeik, Mobile: (+20) 01227101474, Email: m_h_salama@yahoo.com
}

\begin{abstract}
Background: Pulmonary tuberculosis (TB) is one of the major causes of illness and mortality worldwide. Control of TB requires coordinated efforts of both innate and adaptive immune systems. Apoptosis is a genetically regulated physiological process that when dysregulated can contribute to the pathogenesis of various diseases including TB. Objectives: The frequency of apoptotic $\mathrm{T}$ cells among peripheral blood mononuclear cells in patients with active pulmonary TB was studied and correlated with results of sputum bacterial load that reflects disease severity.

Patients and methods: The study included 28 newly diagnosed tuberculin positive patients under anti-TB chemotherapy, classified into 3 groups according to sputum smear grading for AFB. In addition, 11 age matched apparently healthy individuals were included as a control group. PBMCs were stained for flowcytometric analysis using the TUNEL method.

Results: Increased frequency of apoptotic T cells was observed in $71.4 \%$ of patients compared to controls. Patients with higher smear grades (grades $2+$ and $3+$ ) showed increased frequency of apoptosis compared to those with low smear grade $(1+)$.

Conclusion: Increased apoptosis may explain the $\mathrm{T}$ cell depletion/sustained low $\mathrm{T}$ cell responses observed in patients with active pulmonary TB. Its strong association with bacterial load make it a possible in vitro readout of pathogen burden that can be used for fast tracking the response to treatment. Targeting molecules involved in apoptosis may be an approach for an adjunctive anti-TB therapy that rescues $\mathrm{T}$ lymphocytes protective activity especially for infections caused by MDR and XDR MTB strains.
\end{abstract}

Keywords: Blood T lymphocyte, Apoptosis, Pulmonary Tuberculosis, Mycobacterial.

\section{INTRODUCTION}

Pulmonary tuberculosis (TB), an infectious disease caused by Mycobacterium tuberculosis (MTB) remains one of the major causes of illness and mortality worldwide, especially in developing countries (1). Despite the diagnosis and treatment along with the availability of a vaccine for nearly 100 years, the global infection rate of $M T B$ is high ${ }^{(2)}$. The Centers for Disease Control (CDC) and WHO statistics showed that about 10 million new cases and around 1.6 million TB-related deaths are reported annually. The severity of this global problem is further worsened in recent years by the increased incidence and spread of multidrug-resistant (MDR) and extensively-drug resistant (XDR) strains raising a specter of untreatable disease and a return to the pre-antibiotic era ${ }^{(3)}$. Africa accounts for more than $31 \%$ of the global burden of TB ${ }^{(3)}$. Egypt has an intermediate level of incidence and mortality (24 and 3 per 100000 population respectively) ${ }^{(4)}$.

In human TB infections, the pathogen is eliminated in only $10 \%$ of people while a persistent asymptomatic (latent) infection predominates providing a compelling evidence of the ability of the immune system to control, though not to eliminate, the infection ${ }^{(5)}$. Cell- mediated immunity (CMI) involving interactions between macrophages and $M T B$-specificCD4 and CD8 T lymphocytes with production of interferon gamma (IFN- $\gamma$ ) plays a clear and central role in determining the clinical outcome. With effective CMI, the infection either resolves or becomes latent ${ }^{(6)}$. However, around 5-10\% of latently infected individuals exhibit an active disease at some point of their life time, when the immune response is suppressed (7). Understanding the immunopathogenesis of TB is still incomplete. Considerable insight into the mechanisms of protective immunity and the many ways by which $M T B$ induces immune responses and evades elimination by these responses is fundamental ${ }^{(8)}$.

Apoptosis is a genetically regulated physiological cell death process critical for tissue homeostasis and regulation of immune response. Recent studies have shown that the physiological process of apoptosis can be transformed into a pathological process that may contribute to the pathogenesis of various infectious diseases including TB ${ }^{(9)}$. It has been suggested that dysregulation of apoptosis can cause impaired cellular responses leading to maintenance of infection (10). The majority of previous studies investigating apoptosis in response to $M T B$ infection have focused on macrophage apoptosis (11)

The present study was conducted on samples of peripheral blood from patients with active pulmonary TB to evaluate spontaneous T lymphocyte apoptosis as a potential immunopathogenic mechanism contributing to the prolonged hyporesponsiveness state observed 
during human TB. Also, to correlate apoptosis with the disease severity as reflected by sputum bacillary load.

\section{PATIENTS AND METHODS}

Study participants:

The study included 28 tuberculin positive patients with newly diagnosed active pulmonary TB (25 males and 3 females, their ages ranged from 26 to 54 years with mean of $33.8 \pm 9.8$ years. They were selected from those admitted to Abbasia Chest Hospital, Cairo, Egypt.

The diagnosis of TB was established by routine clinical and radiologic criteria, positive sputum smear and confirmed by culture. All patients underwent the standard anti-TB chemotherapy according to CDC guideline for drug susceptibility TB ${ }^{(\mathbf{1 2})}$. Excluded from the study persons with chronic, disseminated or meningeal TB, those with immunodeficiency disorders or receiving immunosuppressive drugs and persons with concomitant debilitating diseases such as cancer or diabetes or renal failure. Patients were classified into three groups according to the WHO grading scale ${ }^{(\mathbf{1 3})}$. Sputum bacterial load was determined by the index of quantification of acid fast bacilli (AFB) seen in sputum smears stained with Zeihl- Neelsen ${ }^{(\mathbf{1 4})}$ (Table 1).

In addition, 11 age-matched healthy volunteer individuals (4 males and 7 females) with no history of TB were included in the study as a control group.

All participants provided written consent for sample collection and subsequent analyses.

\section{Ethical approval:}

The study protocol was approved by the Ethics Committee of Faculty of Medicine, Al Azhar University.

Table (1): Classification of patients into groups according to the index of quantification of AFB in sputum

\begin{tabular}{|c|c|c|c|c|c|}
\hline Groups & $\begin{array}{c}\text { Index of } \\
\text { quantificatio } \\
n\end{array}$ & $\mathrm{n}^{\bullet}$ & & \multicolumn{3}{|c|}{ Number of patients } \\
\cline { 5 - 6 } & & & & Males Females & \multicolumn{2}{|c|}{ Total } \\
\cline { 5 - 6 } & $1+$ & 7 & 1 & 8 & 28.5 \\
\hline II & $2++$ & 9 & 1 & 10 & 35.75 \\
\hline III & $3+++$ & 9 & 1 & 10 & 35.75 \\
\hline
\end{tabular}

- 1+: 1-10 AFB/100 fields examined; 2++: 1-10 $\mathrm{AFB} / 10$ fields examined; 3+++: 1-10 AFB/one field examined

Samples: $5 \mathrm{ml}$ of heparinized venous blood were collected from each subject, transported on ice within 1 hour to the laboratory to be analyzed. Peripheral blood mononuclear cells (PBMCs) were isolated from whole blood by centrifugation through density gradient FicollHypaque (Pharmacia Chemical Co, Piscatway, NJ). Viability of PBMCs was $>99 \%$ as assessed by trypan blue exclusion. The number of PBMCs was adjusted to $1 \times 10^{6}$ cells/ml in RPMI 1640 medium ${ }^{(15)}$.
Cells were stained immediately for detection of apoptotic cells among PBMCs, using the Apo-Direct Kit (Pharmangen, Becton Dicknson, San Diego, USA) based on the TUNEL (Terminal Deoxynucleotide transferase TdT- mediated Nick End labeling) method (16), according to the manufacturer's instructions. Briefly, cells were fixed, permeabilized and stained first with FITC-dUTP in the presence of TdT to catalize binding (for determination of DNA strand breaks) then with PI/RNase (to counterstain total DNA). Analysis of samples was done within 1 hour of staining in flow cytometer equipped with a $488 \mathrm{~nm}$ argon laser light source (FACS caliber, Becton Dickenson) and CELL QUEST software (Becton Dickenson). The flow rate was set at 200 cells/second with a minimum of $10^{4}$ cells for each sample. All samples were analyzed under the same instrument settings. Acquired data were stored, processed and displayed as a histogram (figure 1). Data were reported as \% of apoptotic cells among PBMCs.

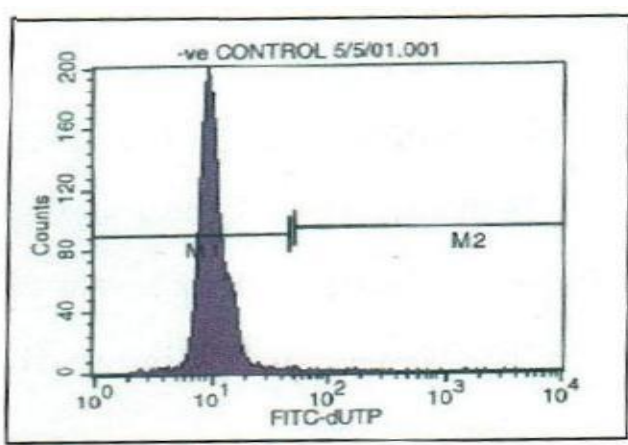

(a) Result of negative control (M1) Represents non apoptotic cells YARA MOHAMED 24 H.001

(a) Result of negative case (M1) Represents non apoptotic cells (M2) Represents apoptotic cells

\section{Detection of apoptotic cells:}




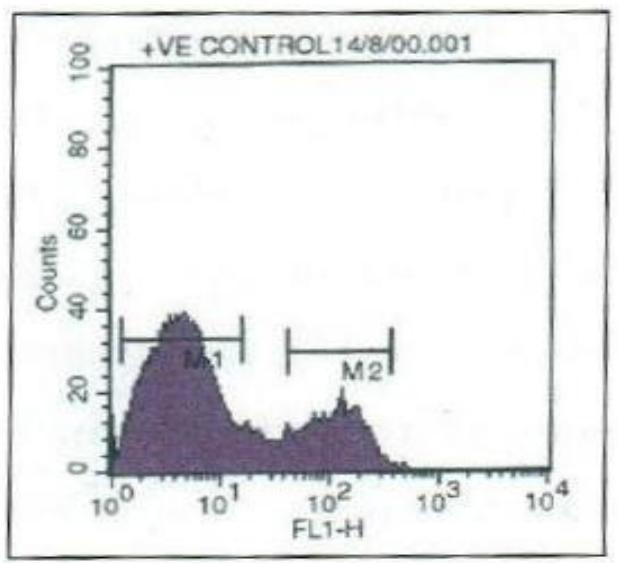

(b) Result of positive control (M1) Represents non apoptotic cells (M2) Represents apoptotic cells

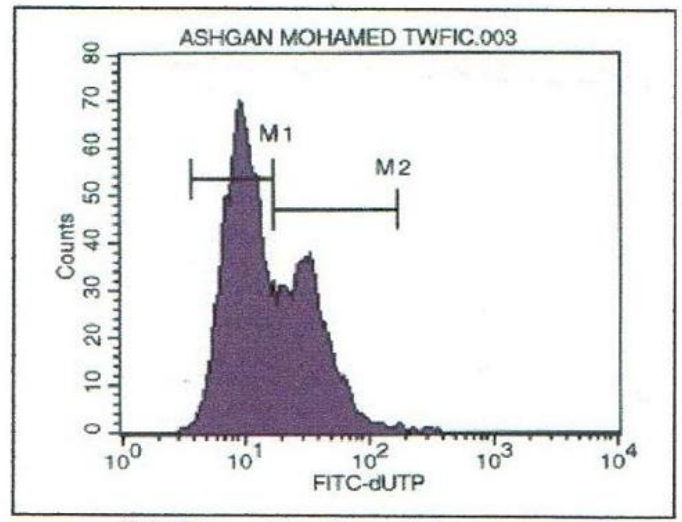

(b) Result of positive case (M1) Represents non apoptotic cells (M2) Represents apoptotic cells

Figure (1): Histogram of apoptotic and non-apoptotic cells among PBMCs.

(a): Result of negative control to the left and negative case to the right)

(b): Result of negative control to the left and negative case to the right)

FITC-d UTP

$\mathrm{X}$-axis: the intensity of FITC-fluorescence, a linear display

Y-axis: the number of cells counted.

M1 peak: the frequency of non-apoptotic cells

M2 peak: the frequency of apoptotic cells.

\section{Statistical Analysis}

Statistical analysis of the results was done using the following tests: Wilcoxon Rank-Sum test for 2 group comparison. Kruskal-Wallis test for comparison between three groups. (r) correlation coefficient between age and apoptotic \% was obtained. $\mathrm{P}$ value $\leq$ 0.05 was considered significant.

\section{RESULTS}

\section{T cell apoptosis among PBMCs:}

Results of flowcytometric evaluation of the frequency (\%) of apoptotic T cells among PBMCs from patients with active pulmonary TB and controls are shown in table (2) and figure (2). The control group showed the least observed frequency $(\%)$ ranging from $0.85 \%$ to $3.74 \%$ with mean of $2.69 \pm 1.43$. In patients, the frequency varied widely among samples, ranging from $0.85 \%$ up to $42.74 \%$ with a mean of $16.36 \pm 12.58$. A significant increase in the frequency (\%) of apoptotic $\mathrm{T}$ cells is observed in patient's samples compared to controls $(\mathrm{P}<0.001)$.

Table (2): The frequency (\%) of apoptotic $\mathrm{T}$ cells in PBMCs from patients with active pulmonary TB and controls.

\begin{tabular}{|l|c|c|c|}
\hline \multirow{2}{*}{} & \multicolumn{2}{|c|}{$\begin{array}{c}\text { Frequency (\%) of } \\
\text { apoptotic T cells }\end{array}$} & \multirow{2}{*}{$\boldsymbol{*}$ P value } \\
\cline { 2 - 3 } & Range & $\begin{array}{c}\text { Mean } \pm \\
\text { SD }\end{array}$ & \\
\hline $\begin{array}{l}\text { Patients } \\
\text { (no }=28)\end{array}$ & $0.85-$ & $16.36 \pm$ & \\
\hline $\begin{array}{l}\text { Controls } \\
\text { (no }=11)\end{array}$ & $0.64-3.45$ & 12.58 & \\
\hline
\end{tabular}

$-P$ value $<0.05$ is considered significant.

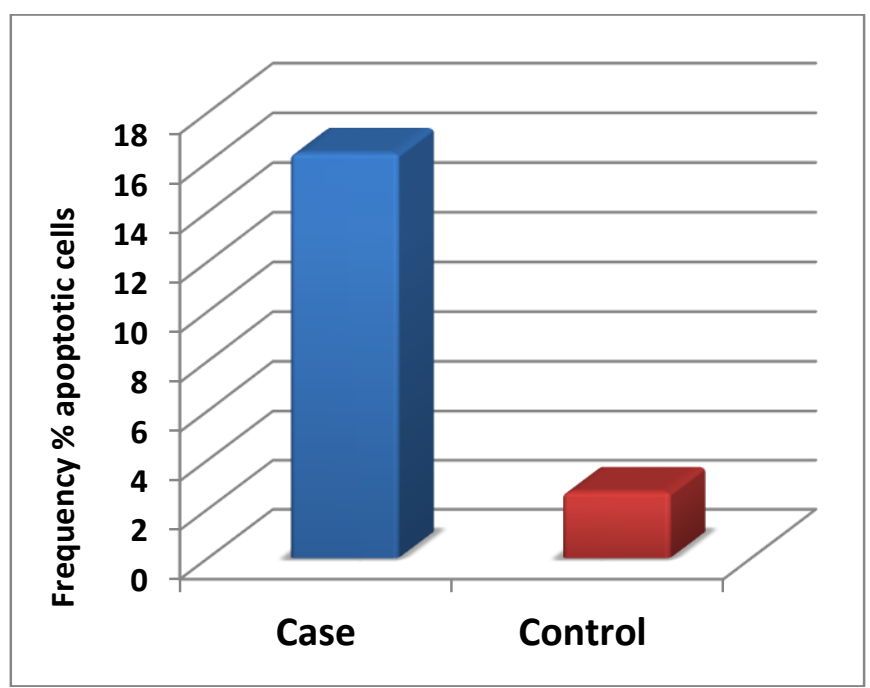

Figure (2): The frequency (\%) of apoptotic $\mathrm{T}$ cells in PBMCs from patients with active pulmonary $\mathrm{TB}$ and controls.

\section{T cell apoptosis among PBMCs in relation to disease severity:}

The frequency (\%) of apoptotic $\mathrm{T}$ cells in patient's subgroups as classified according to the score of index of AFB seen in sputum smears is shown in table (3). Compared to the control group, patients with score index $(1+)$ showed non-significant difference $(\mathrm{P}$ $>0.05)$ while patients with score indices $(2+$ and $3+)$ showed significant increase $(\mathrm{P}<0.001,0.001$ respectively). 
Table (3): The frequency (\%) of apoptotic T cells in PBMCs from patient's subgroups as classified according to the score index and in the control group.

\begin{tabular}{|l|c|c|c|}
\hline & \multicolumn{2}{|c|}{ Frequency (\%) of apoptotic T cells } & \multirow{2}{*}{$\boldsymbol{P}$ value } \\
\cline { 2 - 3 } & Range & Mean \pm SD & $>0.05$ \\
\hline Patient subgroup 1 (no =8) & $0.93-8.8$ & $3.09 \pm 2.77$ & $<0.001$ \\
\hline Patient subgroup 2 (no =10) & $2.07-27.27$ & $13.46 \pm 5.99$ & $<0.001$ \\
\hline Patient subgroup 3 (no =10) & $20.40-42.45$ & $29.88 \pm 8.37$ & \\
\hline Control group (no = 11) & $0.64-4.96$ & $2.68 \pm 1.43$ & \\
\hline
\end{tabular}

$-P$ value $<0.05$ is considered significant.

Correlation of $\mathbf{T}$ cell apoptosis among PBMCs with age:

Non-significant correlation was found between the frequency $(\%)$ of apoptotic $\mathrm{T}$ cells and age in the control group $(\mathrm{r}=0.52388, P>0.05)$. In patient's group as a whole $(\mathrm{r}=0.31766, \mathrm{P}>0.05)$ or patient's subgroups $(\mathrm{r}=0.62658 ; \mathrm{r}=0.55240 ; \mathrm{r}=0.55240$ respectively, $\mathrm{P}>$ $0.05)$.

\section{DISCUSSION}

The current study was performed to investigate $\mathrm{T}$ lymphocyte apoptosis in patients with active pulmonary tuberculosis and to correlate results with sputum smear bacillary load. Results of flowcytometric evaluation of the frequency (\%) of apoptotic T cells among peripheral blood mononuclear cells (PBMCs) showed significant increase in $71.4 \%$ of patient's samples compared to controls $(\mathrm{R}<0.001)$.

Our results are consistent with previous studies. Li et al. (17) demonstrated high susceptibility of lymphocytes from TB patients to apoptosis that was preferentially depleting $M T B$ specific effector cells. Rodrigues et al. ${ }^{(6)}$ and Hirsch et al. ${ }^{(18)}$ reported increased numbers of both spontaneous and antigenstimulated apoptotic $\mathrm{T}$ cells affecting $\mathrm{CD} 4^{+} \mathrm{T}$ helper 1 cells and $\mathrm{CD}^{+} \mathrm{T}$ cells in the peripheral blood of newly diagnosed pulmonary TB patients. Similar results were reported using pleural fluid cells. In experimental TB. Das et al. ${ }^{\left({ }^{19)}\right.}$ detected abnormal death of murine T cells after in vitro stimulation due to selective apoptosis of $\mathrm{T}$ helper 1 cells. Elliott et al. ${ }^{(20)}$ reported that active TB disease was associated with targeted apoptosis of effector $\mathrm{T}$ cells occurring prior to disease progression with significantly higher level of apoptosis lying within the $\mathrm{CD} 45 \mathrm{RO}^{+} \mathrm{PD}-1^{+}$effector/memory $\mathrm{T}$ cell population.

$\mathrm{T}$ cell apoptosis is related to overexpression of pro-apoptotic molecules such as Fas L, TNF- $\alpha$, TGF- $\beta$ or co-inhibitory molecules such as CTLA-4, or to decreased expression of anti-apoptotic molecules such as $\mathrm{Bcl}-2$ or co-stimulatory molecules ${ }^{(9)}$. It has been previously reported that both whole organisms and antigens derived from $M T B$ induced the production of TNF- $\alpha$ from monocytes. Interactions of both TNF- $\alpha$ and Fas L on the surface of infected macrophages with their receptors on activated $\mathrm{T}$ cells provide direct apoptotic signals. Receptor ligation seems to be the predominant pathway for apoptotic cell death ${ }^{(21)}$. Several studies have reported the generation of pro-apoptotic $\mathrm{T}$ cell phenotypes in active TB ${ }^{(22,23)}$ detected $M T B$ specific IFN $-\gamma^{+} \mathrm{CD} 8^{+} \mathrm{T}$ cells with low expression of CD95 (Fas). Thus rendering these cells to be more susceptible to apoptosis and deletion. Higher expression of the important co-inhibitory molecule PD- 1 on $\mathrm{CD}^{+}$but not $\mathrm{CD}^{+} \mathrm{T}$ cells was observed in $\mathrm{TB}$ patients. This negatively affects the ability of $\mathrm{T}$ helper 1 cells to be appropriately activated and become more susceptible to death by neglect ${ }^{(24)}$.

Adekambi et al. ${ }^{(25)}$ Showed increased frequency of caspase- $3^{+}$MTB specific CD4 ${ }^{+} \mathrm{T}$ cells. Apoptosis that is mediated by direct activation of caspases in absence of death receptor ligation as an additional mode of $\mathrm{T}$ cell killing. Caspase-3 is known to be a major executor of apoptosis in antigen stimulated $\mathrm{T}$ cells. Direct caspase activation can be mediated exclusively by soluble factors released from MTB infected macrophages ${ }^{(26)}$.

Gamma/delta T cells were shown to contribute to enhanced $\mathrm{T}$ cell apoptosis among non-CD4 $\mathrm{T}$ cell population. However, this T cell subset represents a very small population of circulating $T$ cell. It is likely that double negative $\mathrm{T}$ cells are also affected ${ }^{(27)}$. $\mathrm{T}$ cell apoptosis was also shown to affect antigen non-specific lymphocytes which may be due to their exposure to proapoptotic molecules $\mathrm{NO}$ and TNF- $\alpha$ produced by $M T B$ infected macrophages ${ }^{(28)}$.

In contrast to our results and those of Heroghe et al. ${ }^{(29)}$ who showed no difference in either spontaneous or $M T B$-induced $\mathrm{T}$ cell apoptosis between pulmonary TB patients and controls.

In this study, the relationship between $\mathrm{T}$ cell apoptosis and the smear bacterial load was investigated. Smear grading is thought to reflect mycobacterial burden in vivo. Patients were classified into three groups according to smear grading for AFB. Grading of a positive smear was shown to reflect the extent of the lesion in open cases where higher smear grades were associated with more extensive lung involvement. Smear grading also showed good correlation with chest radiograph scoring (CXR) of disease severity and progress ${ }^{(30)}$. Our results showed that patients with high mycobacterial load (grades 2+ and 3+) had increased frequency of $\mathrm{T}$ cell apoptosis compared to those with low mycobacterial load (grade 1+). In active TB, where mycobacterial burdens are typically high, specific 
effector T cells become exposed to persistent antigenic stimulation and their frequencies increase similar to that observed in other chronic diseases ${ }^{(31)}$. Individuals vary in the level of $\mathrm{T}$ cell responses they mount for a given antigen load in vivo, therefore differences in $\mathrm{T}$ cell frequency in an individual overtime may reflect changes in his bacterial load ${ }^{(32)}$. Apoptosis may serve as an in vitro readout of pathogen's burden or treatment response. Monitoring of apoptosis, alongside with clinical comprehensive evaluation may be useful as an adjunctive tool for antigen specific $\mathrm{T}$ cell responses and an indicator to $M T B$ antigen load, especially when evaluating the efficacy of anti-TB therapy.

In $\mathrm{TB}$, treatment is typically monitored by clinical, radiological and the traditional microbiological parameters, the later show several limitations. Smear microscopy has a low sensitivity while culture is delayed days to weeks to yield a result ${ }^{(33)}$. In addition, bacteriological methods reflect bacterial load in open cases only but unable to detect persistent populations of bacilli that are remote of cavitary surfaces (sputum negative), bacilli metabolically less active or causing extrapulmonary infections ${ }^{(34)}$.

A reliable antigen-specific immune based assay that can both reflect the bacterial burden in vivo and provides an early indication of treatment outcome/drug efficacy might be helpful for fast tracking (35). Quantification of MTB specific $\mathrm{T}$ cells and their responses were shown not to correlate with bacillary load and therefore poorly suited for monitoring treatment ${ }^{(36)}$. To date, and to the best of our knowledge, there is no quantitative immune assay for the determination of bacterial load in $\mathrm{TB}{ }^{(35)}$. We here, propose that quantification of $M T B$-specific $\mathrm{T}$ cellrelated apoptosis, might in theory, be useful in monitoring treatment. It can be used to check whether treatment mediated resolution is associated with decline in bacterial load and a return of apoptosis within the immune cell subset to levels similar to healthy subjects.

Still additional studies are required to build up on our results to avoid limitations we faced in our preliminary work. One limitation of the study was the inclusion of base line smear status only (at the time of diagnosis). Longitudinal studies should be performed on same subjects participating, with periodic testing at 2-6 months follow up and also after successful completion of a full course of anti-mycobacterial antibiotics. This may yield insights regarding the longevity of $\mathrm{T}$ cell apoptosis and correlation with smear and culture conversion. Similar studies should use MTB-specific antigen to test for antigen-induced apoptosis using $M T B$ antigens such as ESAT-6 or CFP-10.

Another limitation of the study was the modest cohort size. Although it was sufficient to reveal a powerful association of apoptosis with TB but a larger study would be required to confirm.
Finally research should be extended to include subjects with low mycobacterial load such as latent TB infected individuals, especially those facing other risk factor compromising their immune system and who may later progress to active disease. For this challenging group of subjects, there are no clinical, microbiological or radiological parameters for assessing response to therapy. A change/decline in apoptotic response could make it possible for clinicians to determine the effects of therapy.

On another side, fundamental understanding of the pathophysiology of TB is necessary to develop novel therapeutics. By elucidation of apoptosis bases, the molecules involved can be targeted to develop therapies that restore the ability of $\mathrm{T}$ cells to resist microbeinduced apoptosis as a new approach for preventive and adjunctive anti-TB therapy especially for drug-resistant mycobacterial strains.

\section{CONCLUSION}

Increased apoptosis may explain the $\mathrm{T}$ cell depletion/sustained low $\mathrm{T}$ cell responses observed in patients with active pulmonary TB. Its strong association with bacterial load make it a possible in vitro readout of pathogen burden that can be used for fast tracking the response to treatment. Targeting molecules involved in apoptosis may be an approach for an adjunctive anti-TB therapy that rescues $\mathrm{T}$ lymphocytes protective activity especially for infections caused by MDR and XDR MTB strains.

\section{REFERENCES}

1. Lozano R, Naghavi M, Foreman K et al. (2012): Global and regional mortality from 235 causes of death for 20 age groups in 1990 and 2010: a systemic analysis for the global burden of disease study 2010. Lancet, 380: 2095-2128.

2. Zuniga E, Early J, Parish T (2015): The future for earlystage tuberculosis drug discovery. Future Microbiol., 10: 217-229.

3. World Health Organization (2009): Global tuberculosis control: epidemiology, strategy, financing: WHO report 2009. 2009. Report No.: $978 \quad 92 \quad 4 \quad 1563802$. https://apps.who.int/iris/bitstream/ handle/10665/44241/9789241598866_eng.pdf

4. World Health Organization (2004): Tuberculosis services in partnership. The case in Egypt. WHOEM/TUB/243/E. 2004. Amsterdam. The Netherlands and Cairo, Egypt: National Tuberculosis Control Programme, Egypt, World Health Organization, Eastern Mediterranean Region \&Royal Tropical Institute. https://apps.who.int/iris/ handle/10665/116384

5. Baena A, Porcelli SA (2009): Evasion and subversion of antigen presentation by Mycobacterium tuberculosis. Tissue antigens, 74: 189-204

6. Rodrigues D, Medeiros E, Weckx L et al. (2002): Immunophenotypic characterization of peripheral $T$ lymphocytes in Mycobacterium tuberculosis infection and disease. Clin Exp Immunol., 128: 149 - 154. 
7. Anderson $\mathbf{P}$ (2007): Vaccine strategies against latent tuberculosis infection. Trends Microbiol., 15 (1): 7-13.

8. Urdahl K, Shafiani S, Ernst J (2011): Initiation and regulation of $\mathrm{T}$-cell responses in tuberculosis. Mucosal Immunol., 4 (3): 288-293.

9. Hirsch C, Johnson J, Okwera A et al. (2005): Mechanism of Apoptosis of $\mathrm{T}$ cells in human Tuberculosis. Journal of Clinical Immunology, 25 (4): 353-364.

10. Hengartner $M$ (2000): The biochemistry of apoptosis. Nature, 407: $770-6$.

11. Lam A, Prabhu R, Riesenberg LA et al. (2017): Role of apoptosis and autophagy in tuberculosis. Am J Physiol Lung Cell Mol Physiol., 313 (2): L218 - L229.

12. Blumberg $H$, Burman $W$, Chaisson $R$ et al. (2003): American Thoracic Society/Centers for Disease Control and Prevention/ Infectious Diseases. Society of American Treatment of Tuberculosis. Am J Resp Crit Care Med., 167 (4): 603-62.

13. World Health Organization (1998): Laboratory services in tuberculosis Control. II. Microscopy. Document WHO/TB 98.258. WORLD Health Organization, Geneva, Switzerland. https://apps. who.int/iris/bitstream/ $\begin{array}{llll}\text { handle/10665/65942/WHO } & \text { TB } & 98.258 & \text { (part1). }\end{array}$ pdf? sequence $=1$

14. Booth W (1988): A rebel without a cause of AIDS. Science, 239 (4847): 1485-1488.

15. Boyum A (1968): Isolation of mononuclear cells and granulocytes from human blood: isolation of mononuclear cells by one centrifugation and sedimentation at $1 \mathrm{~g}$. Scand J Clinc Lab Invest., 97: 77-89.

16. Darzynkiew Z, Galkowski D, Zhao H (2008): Analysis of apoptosis by cytometry using TUNEL assay. Methods, 44 (3): 250-254.

17. Li B, Bassairi H, Rossman MD et al. (1998): Involvement of the Fas/ Fas ligand pathway in activation induced cell death of Mycobacteria reactive human gamma delta $\mathrm{T}$ cells: a mechanism for the loss of gamma delta $\mathrm{T}$ cells in patients with pulmonary TB. J Immunol., 161: 1558-67.

18. Hirsch C, Toossi Z, Guido V et al. (1999): Apoptosis and $\mathrm{T}$ cell hyporesponsineness in pulmonary tuberculosis. The Journal of Infectious Diseases, 179: 945 - 53.

19. Das G, Vohra H, Saha B et al. (1999): Apoptosis of Th1 like cells in experimental tuberculosis (TB). Clin Exp Immunol , 115: $324-328$.

20. Elliott T, Owolabi O, Donkor $\mathrm{S}$ et al. (2015): Dysregulation of apoptosis is a risk factor for tuberculosis disease progression. J Inf Dis., 212 (9): 1469 - 1479.

21. Ju ST, Pank DJ, Cui H et al. (1995): Fas (CD95)/Fas L interactions required for programmed cell death after Tcell activation. Nature, 373: $444-448$.
22. Munn DH, Pressey J, Bealls R et al. (1996): Selective activation - induced apoptosis of peripheral blood $\mathrm{T}$ cells imposed by macrophages. J Immunol., 156: 523 - 532.

23. Day CL, Moshi ND, Abrahams DA et al. (2014): Patients with tuberculosis disease have Mycobacterium tuberculosis - specific CD8+ T cells with a proapoptotic phenotype and impaired proliferative capacity which is not restored following treatment. Plos One, 9: 94949.

24. Van Parijs L, Abbas AK (1998): Homeostasis and selftolerance in the immune system: Turning lymphocytes off. Science, 280: 243 - 248 .

25. Adekambi T, Ibegbu CC, Cagle $\mathrm{S}$ et al. (2018): High frequencies of caspase-3 expressing Mycobacterium tuberculosis-specific CD4+ $\mathrm{T}$ cells are associated with active tuberculosis. Frontiers in Immunology, 9: 1481.

26. Macdonald S, Woodward E, Coleman M et al. (2012): Networked $\mathrm{T}$ cell death following macrophage infection by Mycobacterium tuberculosis. Plos One, 7 (6): e 38488.

27. Durate R, Kindlean JK and Carracede J (1997): Mycobacterium tuberculosis induces apoptosis in $\mathrm{g} / \mathrm{d} \mathrm{T}$ lymphocytes from patients with advanced clinical forms of active tuberculosis. Clinical and Diagnostic Laboratory Immunology, 4 (1): $14-18$.

28. Sharma S, Sharma M, Bose M (2009): Mycobacterium tuberculosis infection of human monocyte derived macrophage lead to apoptosis of $\mathrm{T}$ cells. Immunology and Cell Biology, 87: $226-234$.

29. Heroghe T, Wajja A, Ntambi $L$ et al. (2002): $T$ cell activation, apoptosis and cytokine dysregulation in the (co)pathogenesis of HIV and pulmonary tuberculosis (TB). Clin Exp Immunol., 122: 350- 357.

30. Gomes M, Saad R, Stirbulov R (2003): Pulmonary Tuberculosis: Relationship between sputum Bacilloscopy and Radiological lesions. Rev Inst Med Trop S. Paulo, 45 (5): $275-281$.

31. Kaech SM, Wherry EJ, Ahmed R (2002): Effector and memory $\mathrm{T}$ cell differentiation: implications for vaccine development. Nat Rev Immunol., 2: 251 - 62.

32. Carrara S, Vincent D, Petrosillo $\mathrm{N}$ et al. (2004): Use of a $\mathrm{T}$ cell based assay for monitoring efficacy of antituberculosis therapy. Clin Infect Dis., 38: $754-6$.

33. Storla DG, Yimer S, Bjune GA (2008): A systemic review of delay in the diagnosis and treatment of tuberculosis. Bmc Publ Health, 8: 15-19.

34. Cuevas LE (2011): The urgent need for new diagnostics for symptomatic tuberculosis in children. Ind J Pediatr., 78: 449-455.

35. Lalvani A (2004): Counting Antigen-Specific T cells: A new Approach for Monitoring Response to tuberculosis Treatment? CID., 38: 757 - 759.

36. Oni T, Patel J, Gideon HP et al. (2010): Enhanced diagnosis of HIV-1 associated tuberculosis by relating TSPOT TB and CD4 counts. Eur Respi J., 36: 594-600. 